\title{
Comparison of PFGE and multilocus sequence typing for analysis of Klebsiella pneumoniae isolates
}

Klebsiella pneumoniae represents an important nosocomial pathogen causing urinary, respiratory and blood infections (Brisse et al., 2006; Podschun \& Ullmann, 1998). Hospital outbreaks due to $K$. pneumoniae are frequent and especially feared when caused by multidrug-resistant strains, such as extended-spectrum $\beta$ lactamase producers (Paterson \& Bonomo, 2005). DNA-based strain typing methods are used to distinguish $K$. pneumoniae clinical isolates in order to understand transmission patterns and to help management of hospital infections. Molecular serotyping, based on PCRRFLP of the cps operon responsible for capsular polysaccharide expression, has a higher discriminatory ability than traditional K typing (Brisse et al., 2004), and ribotyping is also applicable to $K$. pneumoniae (Brisse \& Verhoef, 2001). Nevertheless, the most commonly used method is PFGE analysis of macrorestriction fragments (Arlet et al., 1994). The main advantage of PFGE lies in its high discriminatory power (Hansen et al., 2002), but PFGE is technically demanding and requires a high level of coordination (e.g. http://www.cdc.gov/ pulsenet) to achieve inter-laboratory reproducibility. In contrast, multilocus sequence typing (MLST) provides unambiguous data that are suitable for global epidemiology and evolutionary studies (Maiden et al., 1998). A MLST method was previously developed for K. pneumoniae, and analysis of nosocomial isolates showed that MLST can discriminate among epidemiologically unrelated isolates (Diancourt et al., 2005). However, the discriminatory power of MLST was not compared to that of PFGE. In our previous study (Diancourt et al., 2005), 28 isolates belonged to 11 groups that were not distinguished by MLST nor by ribotyping. Among these 11 groups, 5 comprised isolates from distinct countries or separated by large sampling times. For these apparently unrelated cases the isolates could be suspected as being genotypically undistinguishable due to an insufficient discriminatory power of MLST and ribotyping, rather than due to an undocumented epidemiological link. We report here on the comparison of the discriminatory power of PFGE with previously reported methods.

Sixty-three K. pneumoniae isolates from different European hospitals and clinical sources, which were previously analysed by MLST, ribotyping and molecular serotyping (Brisse et al., 2004; Diancourt et al., 2005), were included (Fig. 1). Allele sequences and profiles are available at http://www.pasteur.fr/mlst. Genome fingerprinting by PFGE using enzyme XbaI was performed as described by Arlet et al. (1994), with slight modifications. The banding patterns obtained were compared with a band tolerance parameter of $1 \%$ and a pattern optimization parameter of $1 \%$ using BioNumerics v4.6 software (Applied Maths). PFGE profiles were considered different when there were three or more band differences between them. Simpson's indices of diversity (Hunter \& Gaston, 1988) were calculated using the online tool at http://

www.comparingpartitions.info.

Of the 67 isolates analysed previously (Diancourt et al., 2005), 63 were available for PFGE analysis; these strains belonged to 39 MLST sequence types (STs) and 45 ribotypes (RTs). Fifty-six distinct PFGE types (PTs) were recognized, with a Simpson's index of discrimination of $99.6 \%$, compared to 97.5 and $98.5 \%$ for MLST and ribotyping, respectively. The 58 isolates for which molecular serotyping data were available (Fig. 1) were subdivided into 37 distinct $\mathrm{C}$ patterns (Simpson's index 98.2\%). There were seven pairs of isolates with the same PT (PT3, PT9, PT10, PT13, PT31, PT45 and PT49). Isolates of each of these pairs except one (PT10) had the same ST and the same RT. The two strains of PT10 had the same
ST (ST29) but differed by their RT (RT28 or RT30). Hence, in no case did MLST subdivide PTs. There was a strong concordance between PTs and the source of the isolates. Indeed, all seven pairs of isolates with the same PT came from the same centre and were isolated within a few weeks of each other (Fig. 1); the only exception was PT10, consistent with RT data.

Conversely, several STs and RTs could be subdivided into distinct PTs. Indeed, among the 11 groups with the same ST and RT, only 3 pairs of isolates had the same PT; the remaining 8 groups (22 isolates) were subdivided into 19 PTs. For example, the five strains with ST15 and RT38 were subdivided into four PTs (Fig. 1); the only two strains sharing the same PT were those coming from Lille. Hence, strains coming from distinct centres had distinct PTs, even when they had the same ST or RT. These results show that PFGE provides a finer-grained image of relationships among strains, providing more precise information for epidemiological purposes. If one excludes isolates that are putatively epidemiologically related, as suggested by their shared PTs, the discrimination power of MLST and ribotyping among unrelated strains is 98.1 and $99.0 \%$, respectively.

In conclusion, $63 \mathrm{~K}$. pneumoniae isolates were characterized by PFGE, MLST, ribotyping and molecular serotyping. High concordance among methods was found, and discrimination among epidemiologically non-related strains was higher with PFGE, which thus appears more suitable for short-term epidemiology. Therefore, for $K$. pneumoniae isolates that are not distinguished by MLST, PFGE analysis is recommended to address fine-scale epidemiological questions. This result is consistent with the fact that PFGE can detect chromosomal rearrangements, which may be caused, for example, by mobile elements with rapid evolutionary 


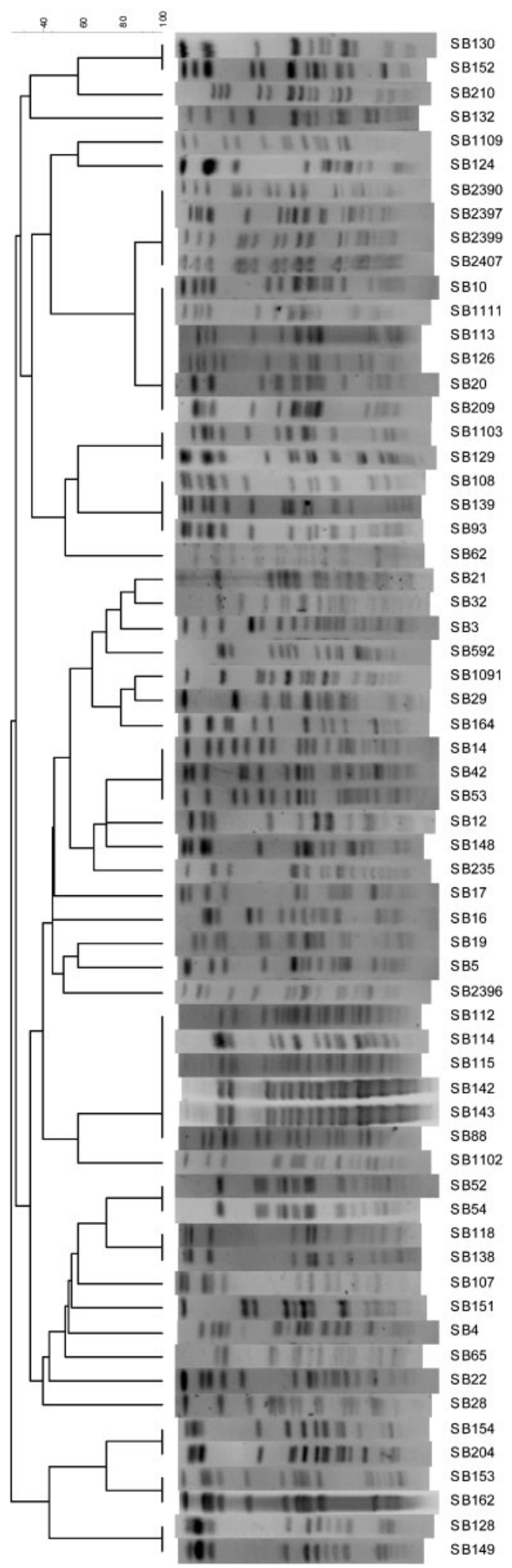

\begin{tabular}{|c|c|c|c|c|c|c|}
\hline $18 \mathrm{C} 048$ & 1 & 101 & C45a & 0050 & BARCELONA & 26 MAY1997 \\
\hline $18 \mathrm{C} 100$ & 1 & 101 & $\mathrm{C} 45 \mathrm{a}$ & 0051 & BARCELONA & 10 MAR1998 \\
\hline O6E037 & 2 & 111 & C52a & 0014 & LILLE & 06 ОСТ1997 \\
\hline ATCC 13883T & 3 & 36 & с3a & 0041 & Unspecified & \\
\hline 05D002 & 8 & 83 & $\mathrm{C} 3 \mathrm{c}$ & 0016 & LYON & 08 JUL1997 \\
\hline 11E006 & 9 & 66 & $\mathrm{C} 8 \mathrm{~b}$ & 0052 & ROMA & 01 OCT 1997 \\
\hline cur15505 & 14 & 77 & $\mathrm{C} 2 \mathrm{e}$ & 0038 & Curacao & \\
\hline cur24339 & 14 & 77 & Failed & 0040 & Curacao & \\
\hline cur24911 & 14 & 77 & $\mathrm{C} 2 \mathrm{e}$ & 0031 & Curacao & \\
\hline cur35389 & 14 & 77 & $\mathrm{C} 2 \mathrm{~b}$ & 0031 & Curacao & \\
\hline $01 A 018$ & 15 & 38 & $\mathrm{C} 24 \mathrm{a}$ & 0039 & LINZ & 20 MAY1997 \\
\hline $15 \mathrm{E} 050$ & 15 & 38 & $\mathrm{C} 24 \mathrm{a}$ & 0036 & COIMBRA & 13 NOV1997 \\
\hline 06E046 & 15 & 38 & $C 24 b$ & 0049 & LILLE & 01 OCT 1997 \\
\hline 13D044 & 15 & 98 & $\mathrm{C} 24 \mathrm{a}$ & 0048 & WARSAW & 20 AUG1997 \\
\hline $04 A 025$ & 15 & 38 & C24a & 0043 & PARIS & 09 APR 1997 \\
\hline 06A395 & 15 & 38 & $C 24 b$ & 0049 & LILLE & 07 AUG1998 \\
\hline 18E092 & 4 & 63 & C10a & 0047 & BARCELONA & 04 ОСТ 1998 \\
\hline 14E044 & 4 & 63 & C157 & 0024 & CRACOW & 08 OCT1997 \\
\hline $01 \mathrm{~A} 114$ & 5 & 6 & c39b & 0021 & LINZ & 09 APR 1997 \\
\hline 10A160 & 5 & 6 & с $39 \mathrm{~b}$ & 0054 & GENOA & 07 JUL_1997 \\
\hline $14 \mathrm{~A} 010$ & 5 & 41 & c39b & 0022 & CRACOW & 14 APR 1997 \\
\hline $19 A 035$ & 6 & 67 & $\mathrm{C} 7 \mathrm{a}$ & 0002 & LAUSANNE & 25 APR 1997 \\
\hline $04 A 041$ & 22 & 249 & $\mathrm{C} 9 \mathrm{a}$ & 0012 & PARIS & 14 APR 1997 \\
\hline 08 A082 & 20 & 35 & C109 & 0018 & DUSSELDORF & 12 MAY 1997 \\
\hline $08 \mathrm{~A} 028$ & 19 & 119 & $\mathrm{C} 28 \mathrm{a}$ & 0034 & DUSSELDORF & 15 APR 1997 \\
\hline 09A434 & 31 & 28 & $\mathrm{c} 30 \mathrm{~b}$ & 0008 & ATHENS & 05 OCT1998 \\
\hline $04 C 047$ & 16 & 135 & C122 & 0030 & PARIS & 16 JUL1997 \\
\hline $07 A 023$ & 17 & 120 & C131 & 0017 & FREIBURG & 19 FEB1997 \\
\hline $09 A 323$ & 18 & 88 & C101 & 0056 & ATHENS & 25 NOV1997 \\
\hline $02 \mathrm{~A} 029$ & 23 & 114 & C1a & 0027 & BRUSSELS & 22 FEB1997 \\
\hline $12 \mathrm{~A} 041$ & 23 & 855 & $\mathrm{C} 1 \mathrm{a}$ & 0028 & UTRECHT & 30 JUN1997 \\
\hline $16 \mathrm{~A} 151$ & 23 & 114 & $\mathrm{C} 1 \mathrm{a}$ & 0029 & SEVILLA & 17 JUL_1997 \\
\hline $01 A 067$ & 24 & 39 & $\mathrm{C} 25 \mathrm{~b}$ & 0046 & LINZ & 22 JUL1997 \\
\hline $14 \mathrm{~A} 069$ & 25 & 85 & $\mathrm{C} 2 \mathrm{a}$ & 0053 & CRACOW & 20 ОСТ 1997 \\
\hline $08 \mathrm{~A} 418$ & 26 & 1 & $\mathrm{C} 10 \mathrm{~b}$ & 0042 & DUSSELDORF & 24 APR 1998 \\
\hline $03 \mathrm{~A} 097$ & 34 & 40 & C132 & 0055 & PARIS & 11 OCT 1997 \\
\hline $03 A 085$ & 33 & 130 & C13a & 0035 & PARIS & 11 SEP1997 \\
\hline $04 A 022$ & 41 & 104 & C110 & 0006 & PARIS & 23 APR 1997 \\
\hline $15 A 006$ & 12 & 124 & C $35 c$ & 0044 & COIMBRA & 04 APR 1997 \\
\hline cur24329 & 13 & 782 & $\mathrm{C} 3 \mathrm{a}$ & 0037 & Curacao & \\
\hline $05 A 096$ & 29 & 30 & C119 & 0010 & LYON & 10 MAY1997 \\
\hline 09A098 & 29 & 93 & с $30 \mathrm{~b}$ & 0007 & ATHENS & \\
\hline 09A199 & 29 & 28 & Na & 0010 & ATHENS & 06 ОСТ 1997 \\
\hline 09A317 & 29 & 28 & Na & 0009 & ATHENS & 29 NOV1997 \\
\hline 09A256 & 29 & 28 & NA & 0009 & ATHENS & 22 NOV1997 \\
\hline 17A092 & 29 & 50 & C119 & 0011 & MADRID & 05 JUN1997 \\
\hline $08 \mathrm{C} 003$ & 32 & 84 & C119 & 0023 & DUSSELDORF & 06 MAY1997 \\
\hline 16A111 & 35 & 23 & $\mathrm{C} 22,37 \mathrm{a}$ & 0013 & SEVILLA & 10 JUN1997 \\
\hline $16 \mathrm{~A} 175$ & 35 & 23 & $\mathrm{C} 22,37 \mathrm{a}$ & 0013 & SEVILLA & 14 AUG1997 \\
\hline $09 D 053$ & 36 & 60 & $\mathrm{C} 27 \mathrm{a}$ & 0045 & ATHENS & 10 SEP1997 \\
\hline $09 D 080$ & 36 & 60 & $\mathrm{C} 27 \mathrm{a}$ & 0045 & ATHENS & 08 OCT 1997 \\
\hline MGH 78578 & 38 & 8 & C52a & 0019 & Unspecified & \\
\hline $18 \mathrm{~A} 365$ & 39 & 9 & C128 & 0032 & BARCELONA & 05 MAR1998 \\
\hline $11 \mathrm{~A} 023$ & 37 & 127 & C14a & 0001 & ROMA & 23 APR 1997 \\
\hline 20A188 & 40 & 113 & C106 & 0015 & LONDON & 06 SEP1997 \\
\hline $05 A 012$ & 45 & 61 & $\mathrm{C} 24 \mathrm{a}$ & 0020 & LYON & 07 APR 1997 \\
\hline 06 A093 & 10 & 123 & C $35 \mathrm{c}$ & 0033 & LILLE & 06 JUL_1997 \\
\hline 22E041 & 42 & 99 & Na & 0004 & ANKARA & 13 NOV1997 \\
\hline 20 A292 & 42 & 100 & C102 & 0005 & LONDON & 13 DEC1997 \\
\hline $22 \mathrm{~A} 027$ & 43 & 31 & $\mathrm{C} 30 \mathrm{a}$ & 0025 & ANKARA & 15 AUG1997 \\
\hline $24 A 013$ & 43 & 31 & $\mathrm{C} 30 \mathrm{a}$ & 0026 & ISTANBUL & 08 NOV1997 \\
\hline 14E015 & 44 & 96 & C121 & 0003 & CRACOW & 24 SEP1997 \\
\hline $14 \mathrm{~A} 076$ & 44 & 96 & C121 & 0003 & CRACOW & 03 NOV1997 \\
\hline
\end{tabular}

Fig. 1. UPGMA dendrogram based on MLST profiles and its correspondence with PFGE patterns. The columns to the right of the PFGE patterns correspond (from left to right) to the strain ID number in our laboratory collection (SB number), original strain name, ST, RT, molecular serotype (C pattern), PT, city of isolation and date of isolation. $\mathrm{C}$ patterns could not be obtained for one strain (indicated by 'failed' in the corresponding column) and were not analysed (NA) for four other strains. 
rates. In contrast, MLST is more appropriate for strain phylogeny and large-scale epidemiology. Indeed, determination of phylogenetic relationships among strains with distinct PFGE patterns is imprecise. For example, strains belonging to the same ST did not always cluster in a single branch based on cluster analysis of PFGE patterns (not shown), and there was only a weak correlation $(r=0.21)$ between the genetic distances calculated based on PFGE patterns and MLST data. Therefore, we see PFGE and MLST as complementary methods, which are appropriate for studies at distinct scales, i.e. local epidemiology versus global population structure, respectively.

\section{Acknowledgements}

We thank Françoise Millot and Virginie Passet for technical assistance. This study was supported financially by Institut Pasteur and a generous gift from the Charitable Conny-Maeva Foundation.

\section{Sophie Vimont, ${ }^{1}$ Basma Mnif, ${ }^{1}$ Cindy Fevre ${ }^{2}$ and Sylvain Brisse ${ }^{2}$}

${ }^{1}$ Service de Bactériologie-Hygiène,
Hôpital Tenon, Assistance PubliqueHôpitaux de Paris, 4 Rue de la Chine, 75970 Paris Cedex 20, France

${ }^{2}$ Institut Pasteur, Genotyping of Pathogens and Public Health, 28 Rue du Dr Roux, 75724 Paris Cedex 15, France

Correspondence: Sylvain Brisse (sbrisse@pasteur.fr)

Arlet, G., Rouveau, M., Casin, I., Bouvet, P. J., Lagrange, P. H. \& Philippon, A. (1994). Molecular epidemiology of Klebsiella pneumoniae strains that produce SHV-4 $\beta$-lactamase and which were isolated in 14 French hospitals. J Clin Microbiol 32, 2553-2558.

Brisse, S. \& Verhoef, J. (2001). Phylogenetic diversity of Klebsiella pneumoniae and Klebsiella oxytoca clinical isolates revealed by randomly amplified polymorphic DNA, gyrA and parC genes sequencing and automated ribotyping. Int J Syst Evol Microbiol 51, 915-924.

Brisse, S., Issenhuth-Jeanjean, S. \& Grimont, P. A. (2004). Molecular serotyping of Klebsiella species isolates by restriction of the amplified capsular antigen gene cluster. J Clin Microbiol 42, 3388-3398.

Brisse, S., Grimont, F. \& Grimont, P. A. D. (2006). The genus Klebsiella. In The Prokaryotes: a Handbook on the Biology of Bacteria, 3rd edn.
Edited by M. Dworkin, S. Falkow, E. Rosenberg, K.-H. Schleifer \& E. Stackebrandt. New York: Springer.

Diancourt, L., Passet, V., Verhoef, J., Grimont, P. A. D. \& Brisse, S. (2005). Multilocus sequence typing of Klebsiella pneumoniae nosocomial isolates. J Clin Microbiol 43, 4178-4182.

Hansen, D. S., Skov, R., Benedi, J. V., Sperling, V. \& Kolmos, H. J. (2002). Klebsiella typing: pulsedfield gel electrophoresis (PFGE) in comparison with O: K-serotyping. Clin Microbiol Infect 8, 397-404.

Hunter, P. R. \& Gaston, M. A. (1988). Numerical index of the discriminatory ability of typing systems: an application of Simpson's index of diversity. J Clin Microbiol 26, 2465-2466.

Maiden, M. C., Bygraves, J. A., Feil, E., Morelli, G., Russell, J. E., Urwin, R., Zhang, Q., Zhou, J., Zurth, K. \& other authors (1998). Multilocus sequence typing: a portable approach to the identification of clones within populations of pathogenic microorganisms. Proc Natl Acad Sci U S A 95, 3140-3145.

Paterson, D. L. \& Bonomo, R. A. (2005). Extended-spectrum $\beta$-lactamases: a clinical update. Clin Microbiol Rev 18, 657-686.

Podschun, R. \& Ullmann, U. (1998). Klebsiella spp. as nosocomial pathogens: epidemiology, taxonomy, typing methods, and pathogenicity factors. Clin Microbiol Rev 11, 589-603. 